\title{
Engineering Long-Range Order in Supramolecular Assemblies on Surfaces: The Paramount Role of Internal Double Bonds in Discrete Long-Chain Naphthalenediimides
}

\author{
José Augusto Berrocal," G. Henrieke Heideman," Bas F. M. de Waal, Mihaela Enache,
} Remco W. A. Havenith, Meike Stöhr, E. W. Meijer,* and Ben L. Feringa*

Cite This: J. Am. Chem. Soc. 2020, 142, 4070-4078

Read Online

ACCESS | Lلll Metrics \& More | 回 Article Recommendations

Supporting Information

ABSTRACT: Achieving long-range order with surface-supported supramolecular assemblies is one of the pressing challenges in the prospering field of non-covalent surface functionalization. Having access to defect-free on-surface molecular assemblies will pave the way for various nanotechnology applications. Here we report the synthesis of two libraries of naphthalenediimides (NDIs) symmetrically functionalized with long aliphatic chains $\left(\mathrm{C}_{28}\right.$ and $\left.\mathrm{C}_{33}\right)$ and their self-assembly at the 1-phenyloctane/highly oriented pyrolytic graphite (1-PO/HOPG) interface. The two NDI libraries differ by the presence/absence of an internal double bond in each aliphatic chain (unsaturated and saturated compounds, respec-

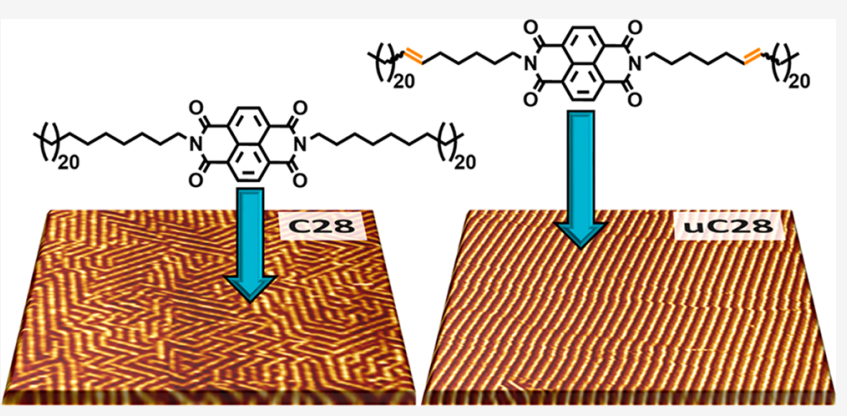
tively). All molecules assemble into lamellar arrangements, with the NDI cores lying flat and forming $1 \mathrm{D}$ rows on the surface, while the carbon chains separate the $1 \mathrm{D}$ rows from each other. Importantly, the presence of the unsaturation plays a dominant role in the arrangement of the aliphatic chains, as it exclusively favors interdigitation. The fully saturated tails, instead, self-assemble into a combination of either interdigitated or non-interdigitated diagonal arrangements. This difference in packing is spectacularly amplified at the whole surface level and results in almost defect-free self-assembled monolayers for the unsaturated compounds. In contrast, the monolayers of the saturated counterparts are globally disordered, even though they locally preserve the lamellar arrangements. The experimental observations are supported by computational studies and are rationalized in terms of stronger van der Waals interactions in the case of the unsaturated compounds. Our investigation reveals the paramount role played by internal double bonds on the self-assembly of discrete large molecules at the liquid/solid interface.

\section{INTRODUCTION}

The non-covalent functionalization of surfaces has become one of the pillars of nanotechnology in the past 20 years. ${ }^{1-4}$ Achieving exact control over the formation of monolayers allows scientists to modulate the properties of surfaces in a predictable manner, ${ }^{5}$ which holds promise for relevant technological breakthroughs. $^{6-8}$ For instance, controlling the density of nitrogen-based n-dopants on graphene via monolayer formation has proved to play a pivotal role in tuning the charge carrier concentration of the modified $2 \mathrm{D}$ material. ${ }^{9}$

Surface-supported supramolecular assemblies rely on stabilizing interactions between the adsorbed molecules and the surface, as well as favorable intermolecular interactions between the adsorbed compounds. ${ }^{10,11}$ Given the significant epitaxial stabilization of $64 \mathrm{meV}(1.5 \mathrm{kcal} / \mathrm{mol})$ per methylene unit that highly oriented pyrolytic graphite (HOPG) exerts at the liquid/HOPG interface, the molecular designs typically adopted in the field feature long alkyl chains-usually up to 18 carbon atoms-to favor adsorption to the substrate. ${ }^{12,13}$ Previous work on long-chain alkanes ${ }^{14-17}$ highlighted the tendency of long aliphatic tails to form thermodynamically stable self-assembled monolayers. Moreover, a number of studies have highlighted the role played by the alkyl chains in the $2 \mathrm{D}$ structure. ${ }^{18-23}$ While a favorable interaction between the molecules and the substrate is certainly necessary, the structure and extent of order of the assemblies generated are mostly the manifestation of the intermolecular interactions between the adsorbed molecules. ${ }^{10,13}$ On-surface supramolecular assemblies are typically created by resorting to non-covalent forces, such as van der Waals (vdW) interactions, ${ }^{24}$ hydrogen bonding $(\mathrm{HB}),{ }^{25-32}$ coordination chemistries, $^{33-36}$ and halogen bonding. ${ }^{37,38}$ So far, various approaches focused on limiting the number of domain boundaries and/or molecular defects to improve the organization and quality of the $2 \mathrm{D}$ architectures gener-

Received: January 20, 2020

Published: January 23, 2020 
ated. ${ }^{39-41}$ More recently, spatially confining the self-assembly process into nanocorrals created on HOPG afforded impressive results in terms of order. ${ }^{42}$ However, the defectfree engineering of surface-supported supramolecular assemblies on unconfined HOPG remains a major challenge for the whole field. ${ }^{43}$

Given the high commercial availability of alkylating reagents in the $\mathrm{C}_{1}-\mathrm{C}_{22}$ range, a large body of work has been carried out using alkyl chain-functionalized compounds. To the best of our knowledge, however, the attention dedicated to their unsaturated analogues featuring internal double bonds has been very limited. Deng et al. compared the assemblies of $E$ oleic acid and Z-oleylamine at the 1-phenyloctane (1-PO)/ HOPG interface. ${ }^{44}$ Monolayers obtained from E-oleic acid at the 1-PO/HOPG interface were characterized by a high stability, while those deriving from the amine with $Z$ configuration were poorly stable. ${ }^{44}$ This comparative study ${ }^{44}$ was consistent in terms of chain length (oleyl $=\mathrm{C}_{18}$ ) and double bond position (between carbon atoms 9 and 10), but the two structures investigated differed in double bond configurations ( $E$ vs $Z$ ) and end-group functionalities (carboxylic vs amino). The hypothesis that various parameters could play a role in the overall stability of the on-surface assemblies could not be ruled out. More recently, Shokri et al. suggested that the introduction of a $Z$-configured double bond in the side chains of bis(urea) molecules leads to the formation of long-range ordered polymers on graphite. ${ }^{45}$ However, the study was conducted with one chain length only $\left(\mathrm{C}_{18}\right)$, and the influence of the internal double bond was visible only after storage of the modified surface for 1 year. ${ }^{45}$ Although both studies independently posed the question of the influence of internal double bonds on on-surface self-assembly processes, no further investigations followed in this direction.

Intrigued by the chance to unravel the possible influence of internal double bonds on surface-supported supramolecular assemblies, we envisioned a system based on long carbon chains featuring internal double bonds symmetrically bound at the periphery of naphthalenediimides ${ }^{46}$ (NDIs). NDIs are electron poor ${ }^{46}$ and have a pronounced tendency to be deposited at the liquid/HOPG interface due to a highly favorable enthalpy of interaction. ${ }^{47,48}$ Symmetrical NDIs functionalized with fully hydrogenated, linear alkyl chains $\left(\mathrm{C}_{n}\right.$-NDI- $\mathrm{C}_{n}$ design) with a number of carbon atoms $(n)$ in the 3-18 range were previously investigated at the 1-tetradecane/ HOPG interface. ${ }^{47}$ Particularly relevant for the present work, alkyl chains with a number of carbon atoms equal to or greater than 13 units consistently afforded lamellar arrangements in which both the long carbon chains and aromatic cores lie flat on the surface, as visualized with scanning tunneling microscopy (STM). ${ }^{47}$ The morphology of the obtained monolayers was explained (lamellar), but the larger longrange-ordered areas obtained represented only a limited part of the surface $(50 \mathrm{~nm} \times 50 \mathrm{~nm})$. In order to exploit the potential of supramolecular assemblies on surfaces, ordered areas larger than $100 \mathrm{~nm} \times 100 \mathrm{~nm}$ (at least) are highly desirable. ${ }^{43}$ Relying on the consistency of the $\mathrm{C}_{n}$-NDI- $\mathrm{C}_{n}$ design with $n>$ 13 (lamellar arrangement), we hypothesized that extending the carbon chain length in the $\mathrm{C}_{n}-\mathrm{NDI}-\mathrm{C}_{n}$ design would be beneficial for expanding the order extent. Moreover, to answer the key question about the role of the internal double bonds, we envisioned a $\mathrm{C}_{n}-\mathrm{NDI}-\mathrm{C}_{n}$ system that features internal unsaturations in the carbon chain. Reducing these double bonds by catalytic hydrogenation should offer the possibility to compare compounds that belong to a very consistent molecular platform (long-chain NDIs) but that differ by a subtle structural modification (formally two hydrogen molecules).

We present the synthesis and on-surface investigation of $\mathbf{u C}_{28}-\mathrm{NDI}-\mathbf{u C}_{28}$ and $\mathbf{u C}_{33}-\mathrm{NDI}-\mathbf{u C}_{33}$ (unsaturated NDIs) and compare them to their hydrogenated counterparts $\mathrm{C}_{28}$-NDI$\mathrm{C}_{28}$ and $\mathrm{C}_{33}-\mathrm{NDI}-\mathrm{C}_{33}$ (saturated NDIs). The fully extended chemical structures are shown in Chart 1 . The studied NDIs

Chart 1. Fully Extended Chemical Structures of $\mathbf{u C}_{28}$-NDI$\mathrm{uC}_{28}, \mathrm{uC}_{33}-\mathrm{NDI}-\mathrm{uC}_{33}, \mathrm{C}_{28}-\mathrm{NDI}-\mathrm{C}_{28}, \mathrm{C}_{33}-\mathrm{NDI}-\mathrm{C}_{33}$, and Key Synthetic Intermediates $\mathrm{uC}_{28}-\mathrm{NH}_{2}$ and $\mathrm{uC}_{33}-\mathrm{NH}_{2}$

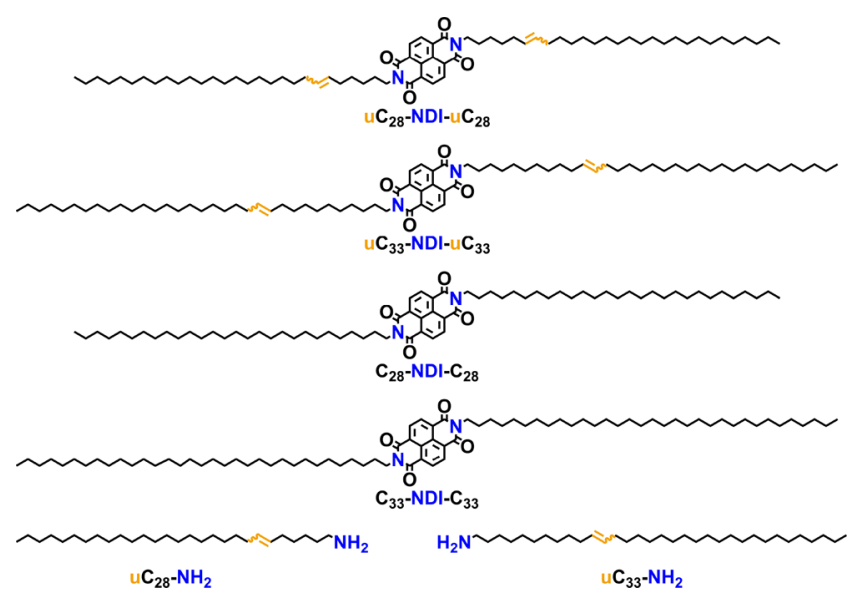

feature either 28 or 33 carbon atoms in the linear chain $\left(C_{28}\right.$ and $\mathrm{C}_{33}$, respectively) and only differ by the presence/absence of one unsaturation in each carbon chain. The unsaturation (when present) is highlighted by the letter $\mathbf{u}$. The key synthetic intermediates in the preparation of the final compounds were the unsaturated amines $\mathbf{u C}_{28}-\mathbf{N H}_{2}$ and $\mathbf{u C}_{33}-\mathbf{N H}_{2}$, also shown in Chart 1. We discover that the self-assembled monolayers obtained at the 1-PO/HOPG interface from the unsaturated compounds are characterized by a significantly higher degree of organization compared to their saturated counterparts, with a size difference for ordered domains corresponding to thousands of squared nanometers. The experimental results are supported by computational studies. Our results point to the establishment of the internal double bond as a counterintuitive yet key structural element for obtaining long-range order in self-assembled monolayers at the liquid/solid interface. Finally, the highly adaptive character of supramolecular assemblies at the liquid/solid interface ${ }^{49}$ allows for the use of mixtures of $E E, E Z$, and $Z Z$ isomers of the unsaturated NDIs, as the system selects the most stable pattern created (almost exclusively) by one stereoisomer.

\section{RESULTS AND DISCUSSION}

Synthesis and Characterization. Compounds $\mathbf{u C}_{28}-\mathbf{N H}_{2}$ and $\mathbf{u C}_{33}-\mathbf{N H}_{2}$ (Chart 1) were the key intermediates in the preparation of the target NDIs. They were synthesized from building blocks $1,{ }^{50} 2$, and 3 in $67 \%$ and $40 \%$ yield, respectively, applying a strategy based on Wittig olefination (Scheme 1). Details on the preparation of $\mathbf{2}$ and $\mathbf{3}$ are presented in the Supporting Information (SI). The amines were obtained as an $\sim 84: 16$ mixture of non-separable $Z$ and $E$ isomers, respectively (assigned by integration of the ${ }^{13} \mathrm{C}$ NMR spectra, see SI). The preference for the $Z$-configuration of the 
Scheme 1. Synthesis of $\mathrm{uC}_{28}-\mathrm{NH}_{2}$ and $\mathrm{uC}_{33}-\mathrm{NH}_{2}$

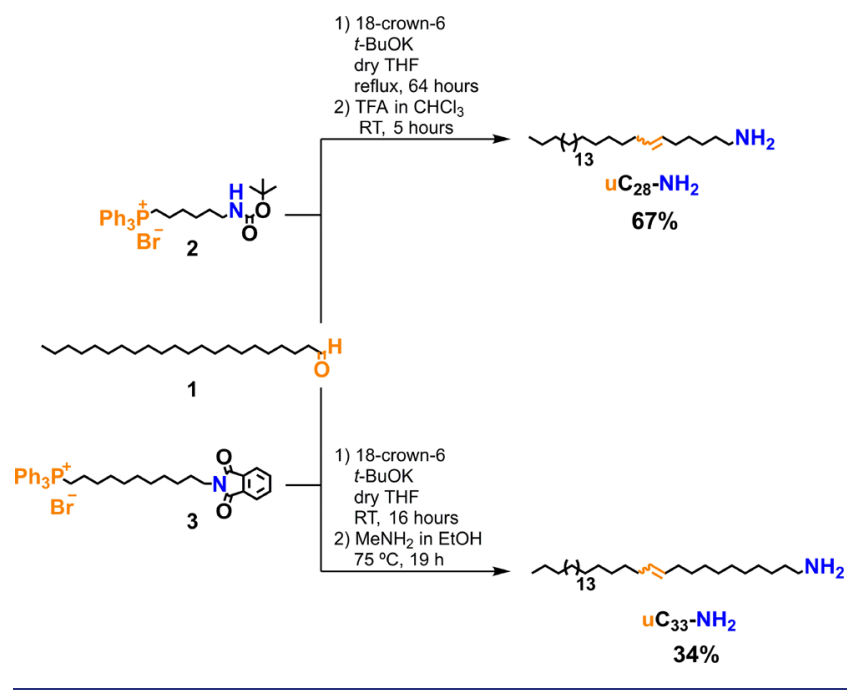

double bond is in line with the Wittig olefination conditions adopted, especially with the use of non-stabilized phosphonium ylides. ${ }^{51}$ The position of the unsaturation along the two carbon chains (between $\mathrm{C}_{6}$ and $\mathrm{C}_{7}$ in $\mathbf{u C}_{28}$, and $\mathrm{C}_{11}$ and $\mathrm{C}_{12}$ in $\mathbf{u C}_{33}$ ) was exactly engineered, as will be corroborated by our STM study (vide infra). The choice of the base-induced Wittig reaction for the elongation step implied a careful choice of protecting groups for the amino moieties on the phosphonium salts. We opted for tert-butyloxycarbonyl- (Boc) and phthalimide- (Phth) protected $\mathbf{2}$ and 3 for $\mathbf{u} \mathrm{C}_{28}-\mathbf{N H}_{2}$ and $\mathbf{u C}_{33}-\mathrm{NH}_{2}$, respectively, after an initial screening of the reaction conditions. A related approach for obtaining discrete oligoethylenes $\left(C_{n} \leq 400\right)$ was previously reported in the effort to build model compounds to study the crystallization of polyethylene. $^{52,53}$ Being complementary, our synthesis allows for the introduction of functional groups in the linear moieties, expanding the applicability of these long aliphatic chains. The cleavage of the -Boc and -Phth protecting groups was carried out with trifluoroacetic acid (TFA) and methylamine solution in ethanol (33 wt\%), respectively (experimental details in SI).

The unsaturated amines were subsequently coupled to commercially available naphthalenedianhydride (NDA) via a modified microwave assisted protocol (Scheme 2). ${ }^{54-56}$ The unsaturated NDIs $\mathbf{u C}_{28}-\mathrm{NDI}-\mathbf{u C}_{28}$ and $\mathbf{u C}_{33}-\mathrm{NDI}-\mathbf{u C}_{33}$ were obtained in $71 \%$ and $80 \%$ yield, respectively, as non-resolvable mixtures of ZZ:ZE:EE isomers ( $70.5: 27: 2.5$, based on the possible combinations of the two reacting amines) after

Scheme 2. Synthesis of $\mathrm{uC}_{28}-\mathrm{NDI}-\mathrm{uC}_{28}, \mathrm{uC}_{33}-\mathrm{NDI}-\mathrm{uC}_{33}$, $\mathrm{C}_{28}-\mathrm{NDI}-\mathrm{C}_{28}$, and $\mathrm{C}_{33}-\mathrm{NDI}-\mathrm{C}_{33}$

$$
\text { (1) }
$$

chromatographic purification. The fully saturated analogs $\mathrm{C}_{28}$ NDI- $\mathrm{C}_{28}$ and $\mathrm{C}_{33}-\mathrm{NDI}-\mathrm{C}_{33}$ were prepared from their alkenyl counterparts by palladium-on-carbon $(\mathrm{Pd} / \mathrm{C})$-catalyzed hydrogenation in ethyl valerate at $100{ }^{\circ} \mathrm{C}$ (Scheme 1) and purified by Soxhlet extraction (see SI).

Self-Assembly on HOPG. We started our investigation by studying the self-assembly of saturated $\mathrm{C}_{28}-\mathrm{NDI}-\mathrm{C}_{28}$ and $\mathrm{C}_{33^{-}}$ NDI-C $_{33}$ at the 1-PO/HOPG interface. Solutions of the two NDIs $(0.4 \mathrm{mg} / \mathrm{mL}$ in $1-\mathrm{PO})$ were drop-cast at $100{ }^{\circ} \mathrm{C}$ onto freshly cleaved HOPG substrates and subsequently imaged. The saturated compounds spontaneously self-assembled into ordered lamellae immediately after deposition. In the STM images, the aromatic cores appear as bright protrusions and the alkyl chains as dark regions (Figure $1 \mathrm{a}-\mathrm{d}$ ). The lamellar
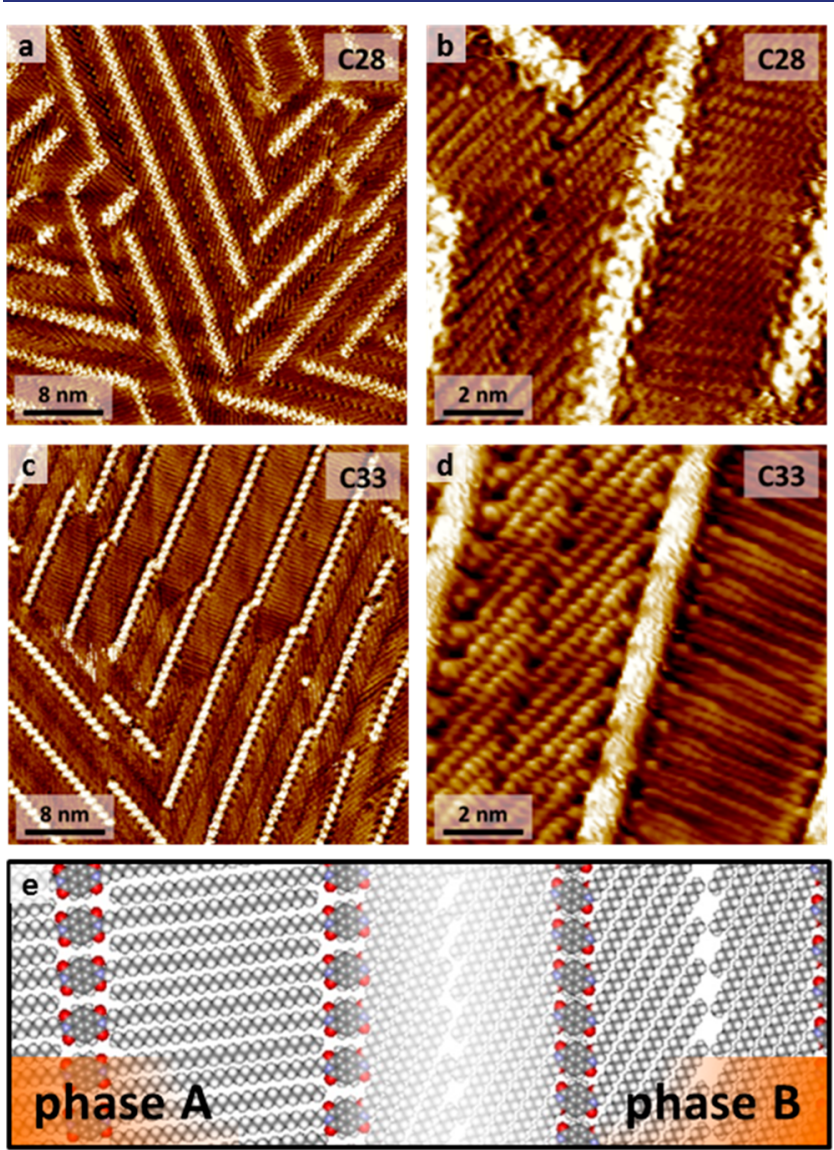

Figure 1. Self-assembly of $\mathrm{C}_{28}-\mathrm{NDI}-\mathrm{C}_{28}$ and $\mathrm{C}_{33}-\mathrm{NDI}-\mathrm{C}_{33}$ at the 1phenyloctane/HOPG interface. (a) STM image of $\mathbf{C}_{28}-\mathrm{NDI}-\mathrm{C}_{28}(40$ $\mathrm{nm} \times 40 \mathrm{~nm}, V_{\text {tip }}=1 \mathrm{~V}, I_{\text {set }}=50 \mathrm{pA}$ ). (b) STM image of $\mathbf{C}_{28}$-NDI$\mathrm{C}_{28}$ showing the two arrangements of alkyl chains (phase A and phase B) $\left(10 \mathrm{~nm} \times 10 \mathrm{~nm}, V_{\text {tip }}=1 \mathrm{~V}, I_{\text {set }}=50 \mathrm{pA}\right)$. (c) STM image of $\mathbf{C}_{33^{-}}$ NDI-C $_{33}\left(40 \mathrm{~nm} \times 40 \mathrm{~nm}, V_{\text {tip }}=-0.6 \mathrm{~V}, I_{\text {set }}=50 \mathrm{pA}\right)$. (d) STM image of $\mathrm{C}_{33}$-NDI- $\mathrm{C}_{33}$ showing the two arrangements of alkyl chains (phase A and phase B) $\left(10 \mathrm{~nm} \times 10 \mathrm{~nm}, V_{\text {tip }}=0.6 \mathrm{~V}, I_{\text {set }}=150 \mathrm{pA}\right)$. (e) Schematic representation of lamellar phase A (with interdigitation of the alkyl chain) and phase B (no interdigitation, diagonal organization of the alkyl chains).

packings are consistent with the aromatic cores lying flat and next to each other on the surface, while the alkyl chains are straight and parallel to each other and modulate the distance between the NDI cores (Figure 1a,c). ${ }^{47}$ The arrangement of the individual alkyl chains was determined from highresolution STM images. We could identify two different 
Table 1. Unit Cell Parameters for the Supramolecular Arrangements of $\mathrm{C}_{28}-\mathrm{NDI}-\mathrm{C}_{28}, \mathrm{uC}_{28}-\mathrm{NDI}-\mathrm{uC}_{28}, \mathrm{C}_{33^{3}}-\mathrm{NDI}-\mathrm{C}_{33}$, and $\mathrm{uC}_{33^{-}}$ $\mathrm{NDI}-\mathrm{uC}_{33}$ at the 1-PO/HOPG Interface ${ }^{a}$

\begin{tabular}{lccccccc}
\multicolumn{1}{c}{ compound } & $a[\mathrm{~nm}]$ & $b[\mathrm{~nm}]$ & $\gamma[\mathrm{deg}]$ & $\begin{array}{c}\text { lamellar } \\
\text { phase }\end{array}$ & $\begin{array}{c}\text { domain size average } \\
{\left[\mathrm{nm}^{2}\right]}\end{array}$ & $\begin{array}{c}\text { domain size median } \\
{\left[\mathrm{nm}^{2}\right]}\end{array}$ & $\begin{array}{c}\text { disordered areas } \\
{[\%]}\end{array}$ \\
$\mathbf{C}_{28}$-NDI-C & $4.45 \pm 0.24$ & $0.88 \pm 0.08$ & $85.21 \pm 3.39$ & A and B & 949 & 737 & $26 \pm 5$ \\
$\mathbf{u C}_{28}$-NDI-uC & $4.53 \pm 0.08$ & $0.86 \pm 0.10$ & $87.33 \pm 1.78$ & A & 6764 & 2923 & - \\
$\mathbf{C}_{33}$-NDI-C & $5.29 \pm 0.49$ & $0.99 \pm 0.10$ & $84.10 \pm 5.28$ & A and B & 1268 & 540 & $24 \pm 8$ \\
$\mathbf{u C}_{33}$-NDI-uC & $5.27 \pm 0.08$ & $0.94 \pm 0.06$ & $84.93 \pm 1.80$ & A & 8026 & 3684 & -
\end{tabular}

${ }^{a}$ The lengths of the unit cell vectors are labeled $a$ and $b$, and the internal angle is specified by $\gamma$ (see also Figure 5a,b).

packing modes for the aliphatic chains of $\mathrm{C}_{28}-\mathrm{NDI}-\mathrm{C}_{28}$ (Figure 1b) and $\mathrm{C}_{33}$-NDI- $\mathrm{C}_{33}$ (Figure $1 \mathrm{~d}$ ): an interdigitated mode, hereby defined as "lamellar phase A", and a non-interdigitated diagonal mode, denominated "lamellar phase B". A pictorial representation of both lamellar phases $\mathrm{A}$ and $\mathrm{B}$ is given in Figure 1e. The lamellae are rotated by $60^{\circ}$ with respect to each another. The observation of the two different packing modes of the aliphatic chains is in line with previous reports on $\mathrm{C}_{n}$-NDI$\mathrm{C}_{n}$, with $13 \leq n \leq 18 .{ }^{47}$ In this respect, extending the length of the alkyl chains did not result in significant differences compared to previous studies.

The unit cell parameters determined for $\mathbf{C}_{28}-\mathrm{NDI}-\mathrm{C}_{28}$ and $\mathrm{C}_{33}-\mathrm{NDI}-\mathrm{C}_{33}$ are listed in Table 1, while for a visualization of the unit cell we refer to Figure 5 and the discussion further on. Although the two lamellar assemblies differ in the orientation of the aliphatic chains, the unit cell parameters do not differ for a fixed alkyl chain length. The measured value are $a=4.45 \pm$ $0.24 \mathrm{~nm}, b=0.88 \pm 0.08 \mathrm{~nm}$, and $\gamma=85.21 \pm 3.39^{\circ}$ for $\mathbf{C}_{28^{-}}$ NDI $C_{28}$, and $a=5.29 \pm 0.49 \mathrm{~nm}, b=0.99 \pm 0.10 \mathrm{~nm}$, and $\gamma=$ $84.10 \pm 5.28^{\circ}$ for $\mathrm{C}_{33}-\mathrm{NDI}-\mathrm{C}_{33}$.

Next, we focused on unsaturated $\mathbf{u C}_{28}-\mathrm{NDI}-\mathbf{u C}_{28}$ and $\mathbf{u C}_{33^{-}}$ NDI- $\mathbf{C C}_{33}$ at the 1-PO/HOPG interface under similar experimental conditions. Exemplary images are shown in Figure 2. Assemblies similar to the ones obtained for the
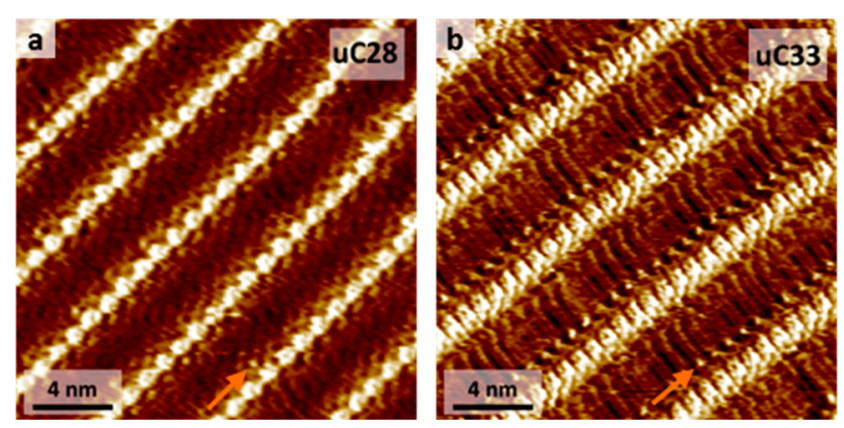

Figure 2. Self-assembly of $\mathbf{u C}_{28}-\mathrm{NDI}-\mathbf{u C}_{28}$ and $\mathbf{u C}_{33}-\mathrm{NDI}-\mathbf{u C}_{33}$ at the 1-phenyloctane/HOPG interface. (a) STM image of $\mathbf{u C}_{28}-\mathrm{NDI}-\mathbf{u C} \mathbf{C}_{28}$ $\left(20 \mathrm{~nm} \times 20 \mathrm{~nm}, V_{\text {tip }}=1 \mathrm{~V}, I_{\text {set }}=100 \mathrm{pA}\right)$. (b) STM image of $\mathbf{u C}_{33^{-}}$ NDI-uC $\mathbf{u}_{33}\left(20 \mathrm{~nm} \times 20 \mathrm{~nm}, V_{\text {tip }}=1 \mathrm{~V}, I_{\text {set }}=90 \mathrm{pA}\right)$. The double bonds appear as bright protrusions next to the bright NDI cores (orange arrows). Both unsaturated molecules assemble in an interdigitated fashion (phase A).

saturated NDIs were observed with $\mathbf{u C}_{28}-\mathrm{NDI}-\mathbf{u} \mathrm{C}_{28}$ and $\mathbf{u C}_{33^{-}}$ NDI-uC $\mathbf{C}_{33}$. The lamellar arrangements correspond to parallel NDI cores flat on the surface (bright protrusions) and the interdigitating aliphatic chains that tune the distance between them (dark regions) (Figure $2 \mathrm{a}$ for $\mathbf{u C}_{\mathbf{2 8}}-\mathrm{NDI}-\mathbf{u C}_{28}$, and Figure $2 \mathrm{~b}$ for $\left.\mathbf{u C}_{33}-\mathrm{NDI}-\mathbf{u C}_{33}\right)$. In stark contrast with the saturated NDIs, additional bright protrusions were observed in the STM images of $\mathbf{u C}_{28}-\mathrm{NDI}-\mathbf{u C}_{28}$ and $\mathbf{u C}_{33}-\mathrm{NDI}-\mathbf{u C} \mathbf{C}_{33}$ (orange arrows in Figure 2a,b). They appeared symmetrically with respect to the aromatic cores, and their distance to the aromatic cores changed upon extending the chain length. These features were less evident in the case of $\mathbf{u C}_{\mathbf{2 8}}-\mathbf{N D I}-\mathbf{u C} \mathbf{C}_{\mathbf{2 8}}$ (Figure 2a), while they appeared more separated and resolved in the case of $\mathbf{u C}_{33^{-}}$ NDI-uC $_{33}$ (Figure 2b). We attribute these additional bright protrusions to the double bonds present in the unsaturated chains. As a general remark, the imaging of the double bonds was in general easier for $\mathbf{u C}_{33}-\mathrm{NDI}-\mathbf{u C}_{33}$ than $\mathbf{u C}_{28}-\mathrm{NDI}-\mathbf{u C} \mathbf{C}_{28}$. Such behavior is attributed to the structural differences between the two molecules and corroborates the more remote position of the double bond with respect to the NDI core in $\mathbf{u C}_{33}$-NDI-uC $\mathbf{u}_{33}$ (between $\mathrm{C}_{11}$ and $\mathrm{C}_{12}$ ) compared to $\mathbf{u C}_{28}$ NDI-uC $\mathrm{C}_{28}$ (between $\mathrm{C}_{6}$ and $\mathrm{C}_{7}$ ).

The determined unit cell parameters for $\mathbf{u C}_{28}-\mathrm{NDI}-\mathbf{u C}_{28}$ and $\mathbf{u C}_{33}$-NDI- $\mathbf{u C} \mathbf{C}_{33}$ are reported in Table 1 . The values are very similar to those obtained for the saturated counterparts, pointing to an apparent similarity between the assemblies of saturated and unsaturated NDIs. The close resemblance of the unit cell parameters of the NDIs with the same chain length $\left(\mathrm{C}_{28}\right.$ or $\left.\mathrm{C}_{33}\right)$ strongly suggests that the self-assembled monolayers are mostly formed by all-E-configured molecules. The E-configured carbon chains are expected to assume zigzag conformations on HOPG in a very similar fashion to alkyl chains and hence cover distances comparable to their saturated counterparts $\left(\mathrm{C}_{28}\right.$ and $\left.\mathrm{C}_{33}\right)$. The $Z$-configured chains, instead, should differ in distance, as the $Z$-configuration forces a bending of the carbon which cannot be compensated by a rotation around the double bond (forbidden in this case). As an indicative example, the carbon chain of $Z$-oleylamine shows this bending as a consequence of the fixed configuration of the double bond. ${ }^{44}$ The deposition of mainly EE-isomer is remarkable, since this isomer is calculated to be roughly $2.5 \%$ of the whole population of unsaturated NDIs (based on the ${ }^{13} \mathrm{C}$ NMR analysis of $\mathbf{u C}_{28} \mathbf{N H}_{2}$ and $\mathbf{u C}_{33} \mathbf{N H}_{2}$ and the binomial distributions of the two amines). The remaining 97.5\% of the material, which accounts for the EZ- and ZZisomers, remains in the overlying liquid phase and is not imaged. We conclude that our long-chain NDIs system at the 1-PO/HOPG interface is highly dynamic and adaptive. Such characteristic allows for the use of EE-, EZ-, and ZZ-isomers mixtures because the system autonomously selects the isomer that forms the most stable pattern on the surface-the EEisomer in this case. A similar concept has been recently reported by Samori, Lehn, et al. with on-surface bisimine formation. ${ }^{49}$ It should be noted that some Z-configured double bonds were present in the monolayer and we speculate that these are responsible for the tiny defects and irregularities observed in the monolayers.

Pivotal Role of the Internal Double Bonds in the 2D Crystallization. The results presented so far have apparently revealed only minor differences in the self-assembly of both 
saturated and unsaturated NDIs at the 1-PO/HOPG interface. However, a very important difference arises in the organization of the aliphatic chains: the fully saturated ones simultaneously arrange in either phase A or B, while the unsaturated chains only pack in the phase A fashion. This difference does not alter the local ordering of the self-assembled monolayer, but has dramatic repercussions on the global ordering of the 2D architectures. The presence of just one type of self-assembly arrangement (phase A) for the carbon chains of $\mathbf{u C}_{28}$-NDI$\mathbf{u C}_{28}$ and $\mathbf{u C}_{33}-\mathrm{NDI}-\mathbf{u C}_{33}$ results in considerably increased domain sizes and thus, in a reduction of the number of domains per area compared to those created by their saturated counterparts. The contrast is striking: for large-scale images, very large domains and significantly less defects are observed in the STM images of $\mathbf{u C}_{28}-\mathrm{NDI}-\mathbf{u C}_{28}$ and $\mathbf{u C}_{33}-\mathrm{NDI}-\mathbf{u C} \mathbf{C}_{33}$ (Figure $3 \mathrm{~b}, \mathrm{~d}$, respectively) compared to those of $\mathrm{C}_{28}-\mathrm{NDI}$ $\mathrm{C}_{28}$ and $\mathrm{C}_{33}-\mathrm{NDI}-\mathrm{C}_{33}$ (Figure 3a,c, respectively).
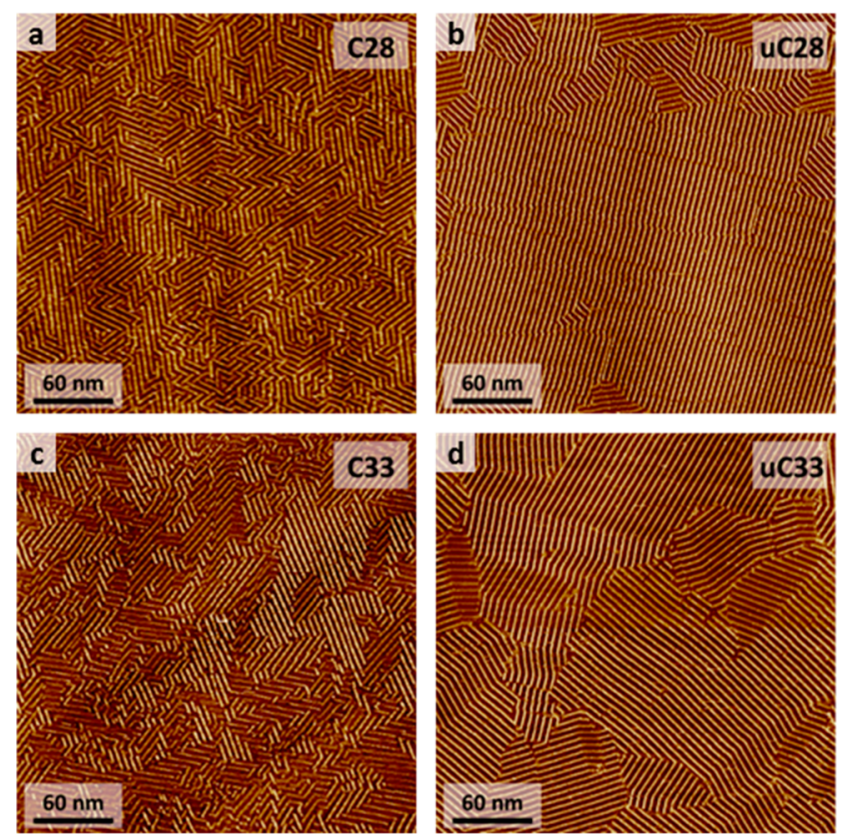

Figure 3. Large-scale STM images $(300 \mathrm{~nm} \times 300 \mathrm{~nm})$ of different NDIs at the 1-PO/HOPG interface: (a) $\mathbf{C}_{28}-\mathrm{NDI}-\mathrm{C}_{28}\left(V_{\text {tip }}=1 \mathrm{~V}, I_{\text {set }}\right.$ $=100 \mathrm{pA}),(\mathrm{b}) \mathbf{u C}_{28}-\mathrm{NDI}-\mathbf{u C}_{28}\left(V_{\text {tip }}=1 \mathrm{~V}, I_{\text {set }}=80 \mathrm{pA}\right),(\mathrm{c}) \mathbf{C}_{33^{-}}$ NDI-C $_{33}\left(V_{\text {tip }}=1 \mathrm{~V}, I_{\text {set }}=100 \mathrm{pA}\right)$, and $(\mathrm{d}) \mathbf{u C}_{33}-\mathrm{NDI}-\mathbf{u C}_{33}\left(V_{\text {tip }}=1\right.$ $\left.\mathrm{V}, I_{\text {set }}=100 \mathrm{pA}\right)$.

The different position of the double bonds in $\mathbf{u C}_{28}$-NDI$\mathbf{u C}_{28}$ and $\mathbf{u C}_{33}-\mathrm{NDI}-\mathbf{u C} \mathbf{C}_{33}$ does not seem to play a role, considering the very similar behavior (Figure $3 \mathrm{~b}, \mathrm{~d}$ ). Results obtained on a positional isomer of $\mathbf{u C}_{28}-\mathrm{NDI}-\mathbf{u} \mathrm{C}_{28}$ with the double bond located between carbon atoms 11 and 12 also rule out a positional influence of the unsaturation (see SI). In contrast, the overview STM images of the saturated NDIs are characterized by relatively small domains accompanied by disordered areas. The lack of a clear preference for either lamellar phase A or B arrangements seems to cause the existence of disordered regions and welter areas (Figure 3a,c; see SI for the assignment of disordered areas).

We conducted a statistical analysis on the domain sizes for the different NDIs to support the qualitative observation on the dramatic influence of the internal double bonds. For a detailed description on the assignment of the domain size and further experimental observations upon scanning see the SI.
The results on the domain size distributions for $\mathrm{C}_{28}-\mathrm{NDI}-\mathrm{C}_{28}$ and $\mathbf{u C}_{28}-\mathrm{NDI}-\mathbf{u C}_{28}$, and $\mathrm{C}_{33}-\mathrm{NDI}-\mathrm{C}_{33}$ and $\mathbf{u C}_{33}-\mathrm{NDI}-\mathbf{u C} \mathrm{C}_{33}$, are summarized by the two histograms shown in Figure 4. The
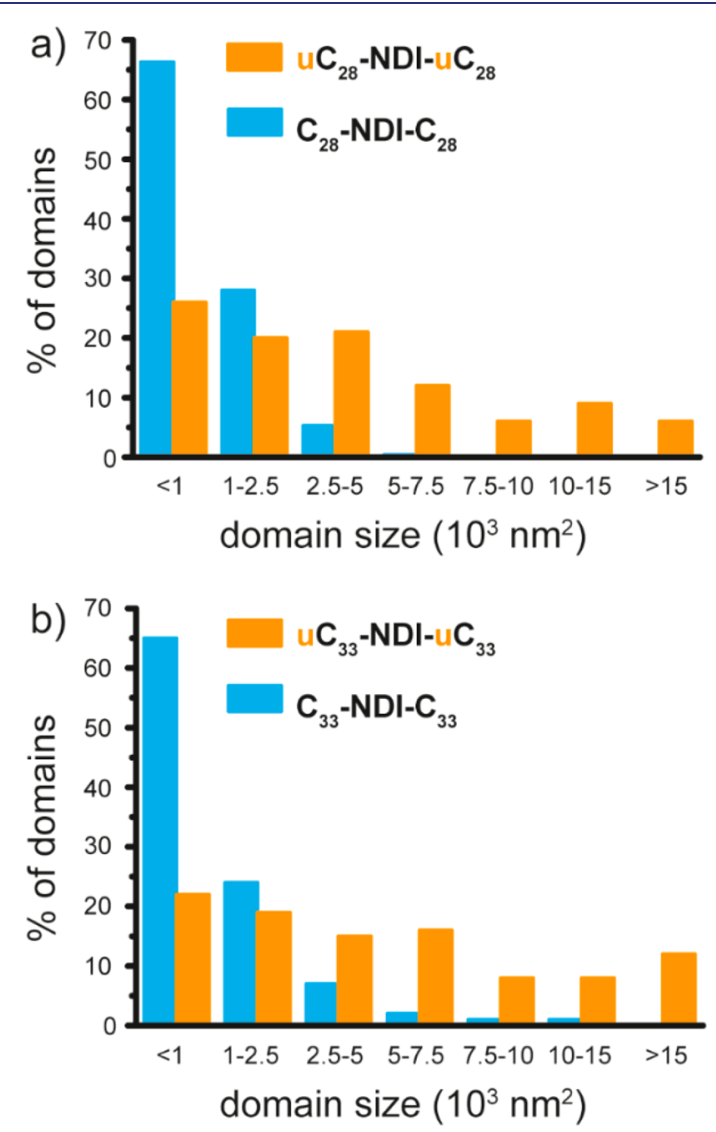

Figure 4. Domain size distribution for (a) $\mathrm{C}_{28}$-NDI- $\mathrm{C}_{28}$ (blue) and $\mathbf{u C}_{28}-\mathrm{NDI}-\mathbf{u C}_{28}$ (orange), and (b) $\mathbf{C}_{33^{-}}$NDI-C $\mathrm{C}_{33}$ (blue) and $\mathbf{u C}_{33^{-}}$ NDI-uC $\mathrm{C}_{33}$ (orange). $Y$-axis: percentage of ordered domains (\% of domains); $X$-axis: domain size $\left(10^{3} \mathrm{~nm}^{2}\right)$.

saturated NDIs mainly arrange in relatively small domains $\left(\leq 1000 \mathrm{~nm}^{2}\right)$ (Figure $4 \mathrm{a}$ and $4 \mathrm{~b}$, blue columns). Moreover, on roughly $24 \%$ of the surface, the molecules do not arrange in an ordered way resulting in disordered areas. On the other hand, the images of the unsaturated NDIs show only a marginal amount of disordered areas. The observed domains reach much larger extensions, with a significant population larger than $15000 \mathrm{~nm}^{2}$ (Figure 4a,b, orange columns).

The experimental results were rationalized by means of a computational study (for computational details see SI). For consistency with our experimental observations on the selfassembled monolayers, we studied only alkenes with Econfigurations. Our working hypothesis focused on the increasing strength of van der Waals interchain interactions upon introducing internal double bonds in the carbon chains. Initial studies on shorter carbon chains $\left(\mathrm{C}_{6}\right)$ in the gas phase showed a promising trend in this respect (see $\mathrm{SI}$ ). Periodic energy decomposition analysis (PEDA $)^{57}$ revealed that the interaction energy between neighboring chains becomes more favorable upon introducing the internal double bonds (Figure S41 and Table S1). Encouraged by these results, we focused on both $\mathbf{C}_{28}-\mathrm{NDI}-\mathrm{C}_{28}$ and $\mathbf{u C}_{28}-\mathrm{NDI}-\mathbf{u C}_{28}$ in the lamellar $\mathrm{A}$ organization. In the calculated molecular arrangements, the NDI cores lay flat and next to each other while the carbon 

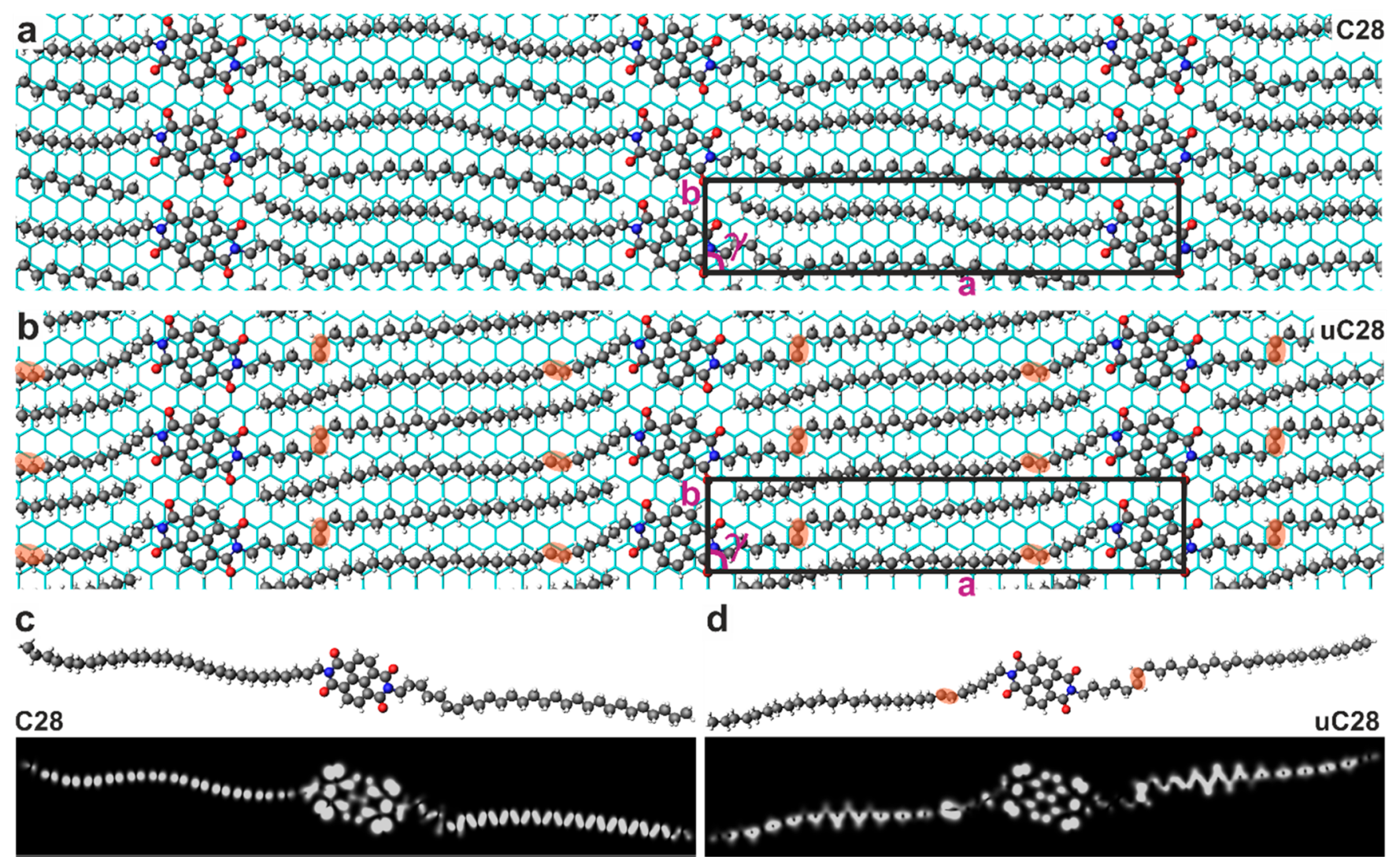

d

Figure 5. (a) Optimized geometries for phase $\mathrm{A}$ of (a) $\mathrm{C}_{28}-\mathrm{NDI}-\mathrm{C}_{28}$ and (b) $\mathbf{u C}_{28}-\mathrm{NDI}-\mathbf{u} \mathrm{C}_{28}$ adsorbed on a graphene surface. The black rectangle shows the unit cells. The orange ellipses show the positions of the double bonds within the NDIs. Hydrogen, carbon, oxygen, and nitrogen atoms are shown in white, gray, red, and blue, respectively. The graphene layer is shown in cyan. The unit cell parameters $a, b$, and $\gamma$ are marked in magenta. (c) Single molecule in lamellar phase A geometry (top) and simulated STM image (bottom, black and white image) at $-1 \mathrm{~V}$ for $\mathrm{C}_{28^{-}}$ NDI-C $_{28}$. (d) Single molecule in lamellar phase A geometry (top) and simulated STM image (bottom, black and white image) at $-1 \mathrm{~V}$ for $\mathbf{u C}_{28^{-}}$ NDI-uC 28 .

chains interdigitate, in line with the experimental observations (Figure 5a for $\mathrm{C}_{28}-\mathrm{NDI}-\mathrm{C}_{28}$, and Figure $5 \mathrm{~b}$ for $\mathbf{u C}_{28}-\mathrm{NDI}$ $\mathbf{u C}_{28}$ ). The distance between the hydrogen atoms of the aromatic $\mathrm{C}-\mathrm{H}$ and the oxygen atoms of the neighboring imide moieties amounts to $2.5 \AA$ for both $\mathrm{C}_{28}$-NDI-C $\mathrm{C}_{28}$ and $\mathbf{u C}_{28}$ NDI-uC $\mathbf{2 8}_{28}$ in line with the literature. ${ }^{47}$ This allows for unconventional hydrogen bonding interactions between adjacent NDI cores, which stabilize the molecular arrangement. Unconventional hydrogen bonding may additionally occur between the oxygen atoms of the imide moieties and the terminal methyl groups of the interdigitating chains from the adjacent row of NDIs for both $\mathrm{C}_{28}$-NDI-C $\mathrm{C}_{28}$ and $\mathbf{u C}_{28}$-NDI$\mathbf{u C}_{28}$. The $\mathrm{H}-\mathrm{O}$ distance varies in the $2.6-3 \AA$ range in this case. The calculated unit cell values are $a=44.8 \AA, b=8.5 \AA$, and $\gamma=90^{\circ}$ for $\mathrm{C}_{28}$-NDI-C $\mathrm{C}_{28}$, and $a=44.5 \AA, b=8.5 \AA$, and $\gamma$ $=90^{\circ}$ for $\mathbf{u C}_{\mathbf{2 8}}-\mathrm{NDI}-\mathbf{u} \mathbf{C}_{\mathbf{2 8}}$, nicely matching with the experimental values (Table 1). This further confirmed the accuracy of the computational study. Finally, we compared the adsorption energies for both $\mathrm{C}_{28}-\mathrm{NDI}-\mathrm{C}_{28}$ and $\mathbf{u C}_{28}-\mathrm{NDI}-\mathrm{uC}_{28}$ in the lamellar phase $\mathrm{A}$ arrangement on graphene. Assemblies of $\mathrm{C}_{28}$-NDI- $\mathrm{C}_{28}$ adsorbed on graphene were $0.166 \mathrm{eV}$ (3.83 $\mathrm{kcal} / \mathrm{mol}$ ) per molecule energetically more favorable than those of $\mathbf{u C}_{28}-\mathrm{NDI}-\mathbf{u} \mathrm{C}_{28}$. However, the experimental observation of improved long-range order with $\mathbf{u C}_{28}-\mathrm{NDI}-\mathbf{u C}_{28}$ compared to $\mathbf{C}_{28}-\mathrm{NDI}-\mathrm{C}_{\mathbf{2 8}}$ and the stronger van der Waals interchain interactions between unsaturated $\mathrm{C}_{6}$ carbon chains (Figure S41 and Table S1) clearly point to more favorable intermolecular interactions in the case of $\mathbf{u C}_{28}-\mathrm{NDI}-\mathbf{u C} \mathrm{C}_{28}$. Considering that the unconventional hydrogen bonding occurring in the calculated lamellar phases of $\mathrm{C}_{28}-\mathrm{NDI}-\mathrm{C}_{28}$ and $\mathbf{u C}_{28}-\mathrm{NDI}-\mathbf{u C}_{28}$ should be very similar, if not identical, from the energetic point of view, we can only ascribe such "more favorable intermolecular interactions" to van der Waals forces.

We simulated an STM image for an individual molecule at a bias voltage of $-1 \mathrm{~V}$ from the calculated lamellar phases of both $\mathbf{C}_{28}-\mathrm{NDI}-\mathrm{C}_{28}$ and $\mathbf{u C}_{28}-\mathrm{NDI}-\mathbf{u C}_{28}$. The individual molecules, as well as the corresponding simulated STM images at bias $-1 \mathrm{~V}$ for $\mathbf{C}_{28}-\mathrm{NDI}-\mathrm{C}_{28}$ and $\mathbf{u C}_{28}-\mathrm{NDI}-\mathbf{u} \mathrm{C}_{28}$, are shown in Figure $5 c$,d. Both $\mathrm{C}_{28}-\mathrm{NDI}-\mathrm{C}_{28}$ and $\mathbf{u C}_{28}-\mathrm{NDI}-\mathbf{u C}_{28}$ showed some level of distortion from a linear geometry of the carbon chains (Figure 5c,d, top part). Interestingly, the two $E$ configured double bonds (encircled by an orange ellipse in Figure $5 \mathrm{~d}$ ) were rotated by almost $90^{\circ}$ with respect to the imaginary line that connects the nitrogen atoms of the NDI core in $\mathbf{u C}_{28}-\mathrm{NDI}-\mathbf{u C} \mathrm{C}_{28}$ (Figure $5 \mathrm{~d}$, top part). As expected, the simulated STM images of $\mathrm{C}_{28}-\mathrm{NDI}-\mathrm{C}_{28}$ and $\mathbf{u C}_{28}-\mathrm{NDI}-\mathbf{u C} \mathbf{C}_{28}$ are almost identical with respect to the aromatic cores (Figure $5 \mathrm{c}$,d, top parts). The main difference concerns the long carbon chains, with the clear presence of the internal double bonds in $\mathbf{u C}_{28}-\mathrm{NDI}-\mathbf{u C}_{28}$ (Figure 5d). The two internal double bonds appear as bright spots, suggesting the presence of two localized areas of higher electronic densities along the carbon chains (Figure 5d). In stark contrast, the distribution of the electronic 
density along the carbon chains of $\mathbf{C}_{28}$-NDI- $\mathbf{C}_{28}$ is more homogeneous and points to a discrete series of single bonds (Figure 5c). Consistently with the on-graphene optimized structure of $\mathbf{u C}_{28}-\mathrm{NDI}-\mathbf{u C}_{28}$, the internal double bonds are rotated by almost $90^{\circ}$, also in the simulated STM image (Figure 5d). This peculiar feature may account for a different visualization of the internal double bond by STM. Such hypothesis seems to be consistent with the experimental STM images reported in Figure 2, in which one of the two double bonds appears more visible than the other one for both $\mathbf{u C}_{28}$ $\mathbf{N D I}-\mathbf{u C} \mathbf{C}_{28}$ and $\mathbf{u C}_{33}-\mathbf{N D I}-\mathbf{u C} \mathbf{C}_{33}$. This difference is more evident in the case of $\mathbf{u C}_{33}-\mathrm{NDI}-\mathbf{u C}_{33}$ and it is probably due to an increased distance for the internal double bonds from the NDI core, which ultimately facilitates the imaging. Hence, the gratifying agreement between the calculations on $\mathbf{u C}_{28}$-NDI$\mathbf{u C}_{28}$ and the experimental STM images on both $\mathbf{u C}_{28}$-NDI$\mathbf{u C}_{28}$ and $\mathbf{u C}_{33}-\mathrm{NDI}-\mathbf{u C} \mathrm{C}_{33}$ allowed us to generalize the conclusions to both unsaturated molecular systems.

\section{CONCLUSIONS}

We presented the synthesis and self-assembly at the 1-PO/ HOPG interface of $\mathrm{C}_{28}$-NDI-C $\mathrm{C}_{28}, \mathrm{C}_{33}$-NDI-C $\mathrm{C}_{33}, \mathbf{u C}_{28}$-NDI$\mathbf{u C}_{28}$, and $\mathbf{u C}_{33}-\mathrm{NDI}-\mathbf{u C}_{33}$. The molecular structures only differ by the presence/absence of precisely positioned internal double bonds in their molecular skeletons. These compounds self-assembled into lamellar arrangements characterized by parallel aromatic cores that lay flat on the surface, and aliphatic chains that modulate the distance between such cores. The longer the chain, the larger the distance, implying that the entire molecular system lays flat on the surface. The packing of the long carbon chains results into two different arrangements: one in which the tails are interdigitated (lamellar phase A), and a second one where the long tails arrange diagonally, without interdigitation (lamellar phase B). We find the presence/ absence of the simple double bonds to be the critical parameter for the selection of the chain arrangements. The fully saturated compounds present a combination of both self-assembly motifs, whereas the unsaturated molecules are capable of selecting the fully interdigitated arrangement. Such difference is magnified and reflected on the long-range order of the generated monolayers, with the unsaturated compounds forming much larger domains (in some cases larger than $15000 \mathrm{~nm}^{2}$ ). This contrasts starkly with the locally ordered, yet globally disordered, monolayers of the saturated compounds. The experimental results were also corroborated by computational studies, which suggest stronger van der Waals interactions between unsaturated carbon chains as a possible explanation. Showing the paramount role played by internal double bonds in the self-assembly of long carbon chain derivatives on surfaces, our results point to the use of "simple" internal double bonds as a critical structural parameter for obtaining long-range order in surface-supported supramolecular processes. We envision the application of our findings toward post-functionalization of non-covalently functionalized surfaces and highly dynamic and smart functional substrates.

\section{ASSOCIATED CONTENT}

\section{(s) Supporting Information}

The Supporting Information is available free of charge at https://pubs.acs.org/doi/10.1021/jacs.0c00765.
Synthetic details, characterization of the new isolated compounds, in situ STM imaging at the liquid/solid interface, and computational details (PDF)

\section{AUTHOR INFORMATION}

\section{Corresponding Authors}

E. W. Meijer - Institute for Complex Molecular Systems and Laboratory of Macromolecular and Organic Chemistry, Eindhoven University of Technology, 5600 MB Eindhoven, The Netherlands; 이이.org/0000-0003-4126-7492; Email: e.w.meijer@tue.nl

Ben L. Feringa - Stratingh Institute for Chemistry and Zernike Institute for Advanced Materials, University of Groningen, 9747 AG Groningen, The Netherlands; 10 orcid.org/0000-00030588-8435; Email: b.l.feringa@rug.nl

\section{Authors}

José Augusto Berrocal - Stratingh Institute for Chemistry, University of Groningen, 9747 AG Groningen, The Netherlands; Institute for Complex Molecular Systems and Laboratory of Macromolecular and Organic Chemistry, Eindhoven University of Technology, 5600 MB Eindhoven, The Netherlands; $\odot$ orcid.org/0000-0003-3435-8310

G. Henrieke Heideman - Stratingh Institute for Chemistry, University of Groningen, 9747 AG Groningen, The Netherlands

Bas F. M. de Waal - Institute for Complex Molecular Systems and Laboratory of Macromolecular and Organic Chemistry, Eindhoven University of Technology, 5600 MB Eindhoven, The Netherlands

Mihaela Enache - Zernike Institute for Advanced Materials, University of Groningen, 9747 AG Groningen, The Netherlands

Remco W. A. Havenith - Stratingh Institute for Chemistry and Zernike Institute for Advanced Materials, University of Groningen, 9747 AG Groningen, The Netherlands; Department of Inorganic and Physical Chemistry, Ghent University, B-9000

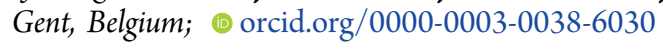

Meike Stöhr - Zernike Institute for Advanced Materials, University of Groningen, 9747 AG Groningen, The

Netherlands; 이이.org/0000-0002-1478-6118

Complete contact information is available at:

https://pubs.acs.org/10.1021/jacs.0c00765

\section{Author Contributions}

"J.A.B. and G.H.H. contributed equally.

\section{Notes}

The authors declare no competing financial interest.

\section{ACKNOWLEDGMENTS}

This work was supported financially by the European Research Council (ERC, advanced grant no. 694345 to B.L.F.), and the Ministry of Education, Culture and Science (Gravitation Program no. 024.001.035). Mr. Ralf Bovee (TU Eindhoven) is acknowledged for MALDI-TOF measurements. The authors thank Pieter van der Meulen (University of Groningen) for assistance during some NMR experiments.

\section{REFERENCES}

(1) Elemans, J. A. A. W.; Lei, S.; De Feyter, S. Molecular and Supramolecular Networks on Surfaces: From Two-Dimensional Crystal Engineering to Reactivity. Angew. Chem., Int. Ed. 2009, 48, 7298-7332.

(2) Woodruff, D. P. Modern Techniques of Surface Science, 3rd ed.; Cambridge University Press, 2016. 
(3) Van Hove, M. A. From Surface Science to Nanotechnology. Catal. Today 2006, 113, 133-140.

(4) Förch, R.; Schönherr, H.; Jenkins, A. T. A. Surface Design: Applications in Bioscience and Nanotechnology; Wiley-VCH, 2009.

(5) Casalini, S.; Bortolotti, C. A.; Leonardi, F.; Biscarini, F. SelfAssembled Monolayers in Organic Electronics. Chem. Soc. Rev. 2017, 46, 40-71.

(6) Bartels, L. Tailoring Molecular Layers at Metal Surfaces. Nat. Chem. 2010, 2, 87-95.

(7) Barth, J. V.; Costantini, G.; Kern, K. Engineering Atomic and Molecular Nanostructures at Surfaces. Nature 2005, 437, 671-679.

(8) Lu, W.; Lieber, C. M. Nanoelectronics from the Bottom Up. Nat. Mater. 2007, 6, 841-850.

(9) Phillipson, R.; Lockhart De La Rosa, C. J.; Teyssandier, J.; Walke, P.; Waghray, D.; Fujita, Y.; Adisoejoso, J.; Mali, K. S.; Asselberghs, I.; Huyghebaert, C.; et al. Tunable Doping of Graphene by Using Physisorbed Self-Assembled Networks. Nanoscale 2016, 8, 20017-20026.

(10) Slater, A. G.; Beton, P. H.; Champness, N. R. Two-Dimensional Supramolecular Chemistry on Surfaces. Chem. Sci. 2011, 2, 14401448.

(11) Tobe, Y.; Tahara, K.; De Feyter, S. Award Accounts Adaptive Building Blocks Consisting of Rigid Triangular Core and Flexible Alkoxy Chains for Self-Assembly at Liquid/Solid Interfaces-Conjugated Molecules for on-Surface Self-Assembly, and Functionalization of Graphitic Surfaces. Bull. Chem. Soc. Jpn. 2016, 89, 1277-1306.

(12) Ilan, B.; Florio, G. M.; Hybertsen, M. S.; Berne, B. J.; Flynn, G. W. Scanning Tunneling Microscopy Images of Alkane Derivatives on Graphite: Role of Electronic Effects. Nano Lett. 2008, 8, 3160-3165.

(13) Mali, K. S.; Adisoejoso, J.; Ghijsens, E.; De Cat, I.; De Feyter, S. Exploring the Complexity of Supramolecular Interactions for Patterning at the Liquid-Solid Interface. Acc. Chem. Res. 2012, 45, 1309-1320.

(14) Yang, T.; Berber, S.; Liu, J.-F.; Miller, G. P.; Tománek, D. SelfAssembly of Long Chain Alkanes and Their Derivatives on Graphite. J. Chem. Phys. 2008, 128, 124709.

(15) Giancarlo, L. C.; Fang, H.; Rubin, S. M.; Bront, A. A.; Flynn, G. W. Influence of the Substrate on Order and Image Contrast for Physisorbed, Self-Assembled Molecular Monolayers: STM Studies of Functionalized Hydrocarbons on Graphite and MoS 2. J. Phys. Chem. B 1998, 102, 10255-10263.

(16) Xie, Z. X.; Xu, X.; Tang, J.; Mao, B. W. ReconstructionDependent Self-Assembly of n-Alkanes on $\mathrm{Au}(111)$ Surfaces. J. Phys. Chem. B 2000, 104, 11719-11722.

(17) Chen, Q.; Yan, H. J.; Yan, C. J.; Pan, G. B.; Wan, L. J.; Wen, G. Y.; Zhang, D. Q. STM Investigation of the Dependence of Alkane and Alkane $\left(\mathrm{C}_{18} \mathrm{H}_{38}, \mathrm{C}_{19} \mathrm{H}_{40}\right)$ Derivatives Self-Assembly on Molecular Chemical Structure on HOPG Surface. Surf. Sci. 2008, 602, 12561266.

(18) Fang, Y.; Cibian, M.; Hanan, G. S.; Perepichka, D. F.; De Feyter, S.; Cuccia, L. A.; Ivasenko, O. Alkyl Chain Length Effects on Double-Deck Assembly at a Liquid/Solid Interface. Nanoscale 2018, 10, 14993-15002.

(19) Xu, L.; Miao, X.; Zha, B.; Deng, W. Hydrogen-BondingInduced Polymorphous Phase Transitions in 2D Organic Nanostructures. Chem. - Asian J. 2013, 8, 926-933.

(20) Shao, X.; Luo, X.; Hu, X.; Wu, K. Chain-Length Effects on Molecular Conformation in and Chirality of Self-Assembled Monolayers of Alkoxylated Benzo[c]Cinnoline Derivatives on Highly Oriented Pyrolytic Graphite. J. Phys. Chem. B 2006, 110, 1539315402.

(21) Nakanishi, T.; Miyashita, N.; Michinobu, T.; Wakayama, Y.; Tsuruoka, T.; Ariga, K.; Kurth, D. G. Perfectly Straight Nanowires of Fullerenes Bearing Long Alkyl Chains on Graphite. J. Am. Chem. Soc. 2006, 128, 6328-6329.

(22) Florio, G. M.; Werblowsky, T. L.; Ilan, B.; Müller, T.; Berne, B. J.; Flynn, G. W. Chain-Length Effects on the Self-Assembly of Short 1-Bromoalkane and n-Alkane Monolayers on Graphite. J. Phys. Chem. C 2008, 112, 18067-18075.
(23) Räisänen, M. T.; Mögele, F.; Feodorow, S.; Rieger, B.; Ziener, U.; Leskelä, M.; Repo, T. Alkyl Chain Length Defines 2D Architecture of Salophen Complexes on Liquid-Graphite Interface. Eur. J. Inorg. Chem. 2007, 2007, 4028-4034.

(24) Dickerson, P. N.; Hibberd, A. M.; Oncel, N.; Bernasek, S. L. Hydrogen-Bonding versus van Der Waals Interactions in SelfAssembled Monolayers of Substituted Isophthalic Acids. Langmuir 2010, 26, 18155-18161.

(25) Barth, J. V.; Weckesser, J.; Cai, C.; Günter, P.; Bürgi, L.; Jeandupeux, O.; Kern, K. Building Supramolecular Nanostructures at Surfaces by Hydrogen Bonding. Angew. Chem., Int. Ed. 2000, 39, $1230-1234$.

(26) Slater, A. G.; Perdigão, L. M. A.; Beton, P. H.; Champness, N. R. Surface-Based Supramolecular Chemistry Using Hydrogen Bonds. Acc. Chem. Res. 2014, 47, 3417-3427.

(27) Zhou, H.; Dang, H.; Yi, J.-H.; Nanci, A.; Rochefort, A.; Wuest, J. D. Frustrated 2D Molecular Crystallization. J. Am. Chem. Soc. 2007, 129, 13774-13775.

(28) Griessl, S.; Lackinger, M.; Edelwirth, M.; Hietschold, M.; Heckl, W. M. Self-Assembled Two-Dimensional Molecular HostGuest Architectures From Trimesic Acid. Single Mol. 2002, 3, 25-31.

(29) Van Esch, J.; De Feyter, S.; Kellogg, R. M.; De Schryver, F.; Feringa, B. L. Self-Assembly of Bisurea Compounds in Organic Solvents and on Solid Substrates. Chem. - Eur. J. 1997, 3, 1238-1243.

(30) De Feyter, S.; Grim, P. C. M.; Van Esch, J.; Kellogg, R. M.; Feringa, B. L.; De Schryver, F. C. Nontrivial Differentiation between Two Identical Functionalities within the Same Molecule Studied by STM. J. Phys. Chem. B 1998, 102, 8981-8987.

(31) Gesquiere, A.; Abdel-Mottaleb, M. M. S.; De Feyter, S.; De Schryver, F. C.; Schoonbeek, F.; van Esch, J.; Kellogg, R. M.; Feringa, B. L.; Calderone, A.; Lazzaroni, R.; Bredas, J. L. Molecular Organization of Bis-Urea Substituted Thiophene Derivatives at the Liquid/Solid Interface Studied by Scanning Tunneling Microscopy. Langmuir 2000, 16, 10385-10391.

(32) Llanes-Pallas, A.; Matena, M.; Jung, T.; Prato, M.; Stöhr, M.; Bonifazi, D. Trimodular Engineering of Linear Supramolecular Miniatures on $\mathrm{Ag}(111)$ Surfaces Controlled by Complementary Triple Hydrogen Bonds. Angew. Chem., Int. Ed. 2008, 47, 7726-7730.

(33) Vijayaraghavan, S.; Ecija, D.; Auwärter, W.; Joshi, S.; Seufert, K.; Drach, M.; Nieckarz, D.; Szabelski, P.; Aurisicchio, C.; Bonifazi, D.; et al. Supramolecular Assembly of Interfacial Nanoporous Networks with Simultaneous Expression of Metal-Organic and Organic-Bonding Motifs. Chem. - Eur. J. 2013, 19, 14143-14150.

(34) De Ruiter, G.; Lahav, M.; Van Der Boom, M. E. Pyridine Coordination Chemistry for Molecular Assemblies on Surfaces. Acc. Chem. Res. 2014, 47, 3407-3416.

(35) Stepanow, S.; Lingenfelder, M.; Dmitriev, A.; Spillmann, H.; Delvigne, E.; Lin, N.; Deng, X.; Cai, C.; Barth, J. V.; Kern, K. Steering Molecular Organization and Host-Guest Interactions Using TwoDimensional Nanoporous Coordination Systems. Nat. Mater. 2004, 3, 229-233.

(36) Matena, M.; Björk, J.; Wahl, M.; Lee, T.-L.; Zegenhagen, J.; Gade, L. H.; Jung, T. A.; Persson, M.; Stöhr, M. On-Surface Synthesis of a Two-Dimensional Porous Coordination Network: Unraveling Adsorbate Interactions. Phys. Rev. B: Condens. Matter Mater. Phys. 2014, 90, 125408.

(37) Gutzler, R.; Fu, C.; Dadvand, A.; Hua, Y.; MacLeod, J. M.; Rosei, F.; Perepichka, D. F. Halogen Bonds in 2D Supramolecular Self-Assembly of Organic Semiconductors. Nanoscale 2012, 4, 5965.

(38) Yoon, J. K.; Son, W.; Chung, K.-H.; Kim, H.; Han, S.; Kahng, S.-J. Visualizing Halogen Bonds in Planar Supramolecular Systems. J. Phys. Chem. C 2011, 115, 2297-2301.

(39) Zhang, J. L.; Zhong, S.; Zhong, J. Q.; Niu, T. C.; Hu, W. P.; Wee, A. T. S.; Chen, W. Rational Design of Two-Dimensional Molecular Donor-Acceptor Nanostructure Arrays. Nanoscale 2015, 7, 4306-4324.

(40) Wang, Q. H.; Hersam, M. C. Room-Temperature MolecularResolution Characterization of Self-Assembled Organic Monolayers on Epitaxial Graphene. Nat. Chem. 2009, 1, 206-211. 
(41) Gates, B. D.; Xu, Q.; Stewart, M.; Ryan, D.; Willson, C. G.; Whitesides, G. M. New Approaches to Nanofabrication: Molding, Printing, and Other Techniques. Chem. Rev. 2005, 105, 1171-1196.

(42) Verstraete, L.; Greenwood, J.; Hirsch, B. E.; De Feyter, S. SelfAssembly under Confinement: Nanocorrals for Understanding Fundamentals of 2D Crystallization. ACS Nano 2016, 10, 1070610715.

(43) Goronzy, D. P.; Ebrahimi, M.; Rosei, F.; Arramel; Fang, Y.; De Feyter, S.; Tait, S. L.; Wang, C.; Beton, P. H.; Wee, A. T. S.; et al. Supramolecular Assemblies on Surfaces: Nanopatterning, Functionality, and Reactivity. ACS Nano 2018, 12, 7445-7481.

(44) Miao, X.; Chen, C.; Zhou, J.; Deng, W. Influence of Hydrogen Bonds and Double Bonds on the Alkane and Alkene Derivatives SelfAssembled Monolayers on HOPG Surface: STM Observation and Computer Simulation. Appl. Surf. Sci. 2010, 256, 4647-4655.

(45) Shokri, R.; Guskova, O.; Jamal, A.; Jahanshahi, K.; Isare, B.; Bouteiller, L.; Simon, L.; Sommer, J.-U.; Reiter, G. Consequences of a Single Double Bond within a Side Group on the Ordering of Supramolecular Polymers. J. Phys. Chem. C 2015, 119, 22596-22603.

(46) Bhosale, S. V.; Jani, C. H.; Langford, S. J. Chemistry of Naphthalene Diimides. Chem. Soc. Rev. 2008, 37, 331-342.

(47) Miyake, Y.; Nagata, T.; Tanaka, H.; Yamazaki, M.; Ohta, M.; Kokawa, R.; Ogawa, T. Entropy-Controlled 2D Supramolecular Structures of $\mathrm{N}, \mathrm{N}^{\prime}$-Bis(n-Alkyl)Naphthalenediimides on a HOPG Surface. ACS Nano 2012, 6, 3876-3887.

(48) Berrocal, J. A.; Teyssandier, J.; Goor, O. J. G. M.; De Feyter, S.; Meijer, E. W. Supramolecular Loop Stitches of Discrete Block Molecules on Graphite: Tunable Hydrophobicity by Naphthalenediimide End-Capped Oligodimethylsiloxane. Chem. Mater. 2018, 30, 3372-3378.

(49) Ciesielski, A.; El Garah, M.; Haar, S.; Kovař́ček, P.; Lehn, J.M.; Samorì, P. Dynamic Covalent Chemistry of Bisimines at the Solid/Liquid Interface Monitored by Scanning Tunnelling Microscopy. Nat. Chem. 2014, 6, 1017-1023.

(50) Van Genabeek, B.; De Waal, B. F. M.; Palmans, A. R. A.; Meijer, E. W. Discrete Oligodimethylsiloxane-Oligomethylene Diand Triblock Co-Oligomers: Synthesis, Self-Assembly and Molecular Organisation. Polym. Chem. 2018, 9, 2746-2758.

(51) Carey, F. A.; Sundberg, R. J. Advanced Organic Chemistry - Part B: Reactions and Synthesis, 5th ed.; Springer, 2007.

(52) Igner, E.; Paynter, O.; Simmonds, D. J.; Whiting, M. C. Studies on the Synthesis of Linear Aliphatic Compounds. Part 2. The Realisation of a Strategy for Repeated Molecular Doubling. J. Chem. Soc., Perkin Trans. 1 1987, 2447-2454.

(53) Bidd, I.; Whiting, M. C. The Synthesis of Pure N-Paraffins with Chain-Lengths between One and Four Hundred. J. Chem. Soc., Chem. Commun. 1985, 543-544.

(54) Berrocal, J. A.; Zha, R. H.; De Waal, B. F. M.; Lugger, J. A. M.; Lutz, M.; Meijer, E. W. Unraveling the Driving Forces in the SelfAssembly of Monodisperse Naphthalenediimide-Oligodimethylsiloxane Block Molecules. ACS Nano 2017, 11, 3733-3741.

(55) Salerno, F.; Berrocal, J. A.; Haedler, A. T.; Zinna, F.; Meijer, E. W.; Di Bari, L. Highly Circularly Polarized Broad-Band Emission from Chiral Naphthalene Diimide-Based Supramolecular Aggregates. J. Mater. Chem. C 2017, 5, 3609-3615.

(56) Bartocci, S.; Berrocal, J. A.; Guarracino, P.; Grillaud, M.; Franco, L.; Mba, M. Peptide-Driven Charge-Transfer Organogels Built from Synergetic Hydrogen Bonding and Pyrene-Naphthalenediimide Donor-Acceptor Interactions. Chem. - Eur. J. 2018, 24, 29202928.

(57) Raupach, M.; Tonner, R. A Periodic Energy Decomposition Analysis Method for the Investigation of Chemical Bonding in Extended Systems. J. Chem. Phys. 2015, 142, 194105. 